\author{
Yulia Pankova ${ }^{1}$, Alexandr Shchegolikhin ${ }^{2}$, Alexey lordanskii ${ }^{1}$, Anna Zhulkina ${ }^{1}$, \\ Anatoliy Ol'khov ${ }^{2}$ and Gennady Zaikov ${ }^{3}$
}

\title{
THE CHARACTERIZATION OF NOVEL BIODEGRADABLE BLENDS BASED ON POLYHYDROXYBUTYRATE
}

\author{
${ }^{1} \mathrm{~N}$. Semenov's Institute of Chemical Physics, Russian Academy of Sciencis, M oscow, Russia; \\ aljordan08@gmail.com \\ ${ }^{2} \mathrm{M}$. Lomonosov's Academy of Fine Chemical Technology, M oscow, Russia \\ ${ }^{3}$ N. M. Emanuel Institute of Biochemical Physics, Russian Academy of Sciences, \\ 4 Kosygina str., 119991 M oscow, Russia; chembio@sky.chph.ras.ru
}

Received: February 05, 2010 / Revised: M arch 19, 2010 / Accepted: September 03, 2010

(C) Pankova Y., Shchegolikhin A., Iordanskii A., Zhulkina A., Ol'khov A., Zaikov G., 2011

\begin{abstract}
The present paper focuses on the study of novel blends based on poly(3-hydroxybutyrate) (PHB) and polymers with different hydrophilicity (LDPE and PA). Polymer blends were produced from five ratios of $\mathrm{PHB} / \mathrm{LDPE}$ in order to regulate the resistance to hydrolysis or (bio)degradation through the control of water permeability. The relation between the water transport and morphology (TEM data) shows the impact of polymer component ratio on the regulating water flux in a hydrophobic matrix. To elucidate the role of hydrophilicity of the second component presented in the PHB blends, we studied the PHB/PA blends where PA is the polyamide resin composed of statistical copolymer of hexamethyleneadipinate and $\varepsilon$-caprolactam in the ratio of $1: 1$. The complex of techniques including DCS and FTIRimaging (for $\mathrm{T}$-scale) demonstrates the interaction between PHB and PA in the temperature ranges of crystallization and melting. The general approach based on Flory-Huggins equation is presented as the way for choosing the pairs of compatible or partly compatible polymers.
\end{abstract}

Keywords: polyhydroxybutyrate, biodegradation, polymer blends, thermophysical properties, kinetics, water diffusion.

\section{Introduction}

The families of biodegradable polymers, namely poly- $\alpha$-hydroxyacides (PLA, PGA, and their copolymers, PLGA) as well as poly- $\beta$-hydroxyalkanoates (PHA): poly(3-hydroxybutyrate) [PHB] and its copolymers, especially with hydroxyvaleriate [PHBV], have superior performance characteristics sufficient for replacing a significant portion of petroleum-based plastics used currently in medicine, packaging and food-service industry [1-3]. Along with biodegradability, the PHAs and their principal member of PHB are biocompatible and friendly environmental [4-6]. In a living organism and soil, their macromolecules decompose forming the nontoxic intermediates and final products included in carbohydrate metabolism. Besides, bacterial PHB and its copolymers have also proved to be useful as model materials for investigating the physical properties such as crystallization and diffusion.

However, the mechanical deficiency, a narrow processing window as well as still the high cost of PHB/PHA restrict its application as the friendly environmental, biomedical material. For solution of the above-mentioned three problems, we propose the specific blending of PHB, as a pivotal component, and the set of synthetic polymers (PELD and polyamide-66) with a different macromolecule polarity to design the (bio)degradable blends/compositions with improved transport and physical characteristics which are useful for description of biodegradation [7] and drug delivery [8].

\section{Experimental}

In the current study, we used PHB in the powder form which was kindly supplied by Biomer Co Krailing (Germany) Lot \#216 with $M_{w}=206 \mathrm{kDa}$ and density $1.248 \mathrm{~g} / \mathrm{cm}^{3}$. The blend films were produced using (a) the low density polyethylene (LDPE) namely the commercial product ( $\mathrm{RF}$ 15803-020 grade) in the form of granules with $M_{\eta}=2.0 \cdot 10^{5} \mathrm{Da}$; and (b) the polyamide resin composed of statistical copolymer of hexamethyleneadipinate and $\varepsilon$-caprolactam in the ratio of $1: 1$ with $M_{n}=(1.94 \pm 0.06) \cdot 10^{4} \mathrm{Da}$ and containing $38 \%$ of amide groups with the content of terminal groups equal to 
$5.0 \pm 0.1 \cdot 10^{-2} \mathrm{~mol} / \mathrm{kg}$ for $-\mathrm{NH}_{2}$ groups and $5.3 \pm 0.1 \cdot 10^{-2}$ $\mathrm{mol} / \mathrm{kg}$ for $-\mathrm{COOH}$ groups. The blends were prepared by solvent casting from chloroform-ethanol solvent combination (both solvents of medical grade quality) and by melt/solid extrusion with a single-screw extruder. A series of LDPE-PHB blends were prepared with the following component ratios (w/w): 68:32; 84:16; 92:8; 96:4 and 98:2.

FTIR spectra of the blend films have been recorded by "Bruker IFS-48" (Germany) spectrometer at a resolution of $2 \mathrm{~cm}^{-1}$; the number of scans is about 70 . The computer analysis of the final spectra is performed with the interior programs in the range of $500-3500 \mathrm{~cm}^{-1}$. A Perkin-Elmer differential scanning calorimeter (Model DSC7) calibrated with indium was applied for the study of thermal behavior of PHB-PA blends as well as for neat polymers (PHB and PA) separately. Specimens of about $5 \mathrm{mg}$ were encapsulated in aluminum pans and heated / cooled at a constant rate of $10 \% \mathrm{~min}$. The range of heating includes the temperature interval from the room temperature to $455 \mathrm{~K}$. The fusion enthalpies $\Delta H_{P H B}$ for PHB and $\Delta H_{P A}$ for PA were measured to calculate the crystallinity degrees $\alpha_{P H B}$ and $\alpha_{P A}$ using the following equations:

$$
\begin{gathered}
\alpha_{P H B}=\frac{\Delta H_{P H B}}{\Delta H_{P H B}^{0}\left(1 / W_{P H B}\right)} \cdot 100 \% \\
\alpha_{P A}=\frac{\Delta H_{P A}}{\Delta H_{P A}^{0}\left(1 / W_{P A}\right)} \cdot 100 \%
\end{gathered}
$$

where $W_{i}(i=\mathrm{PHB}$ or PA) is a weight fraction of each component in the blend and $\Delta H_{P H B}^{0}$ or $\Delta H_{P A}^{0}$ fully crystalline $\mathrm{PHB}(364.53 \mathrm{~J} / \mathrm{g})$ or $\mathrm{PA}(226.26 \mathrm{~J} / \mathrm{g})$ [9].

\section{Results and Discussion}

\subsection{General Approach in the Framework of Flory-Huggins Theory}

The analysis of water solubility in an accessible inter-crystalline area for about 50 polymers with different chemical structures (hydrophilicity) demonstrates that classification of such polymers can be performed on the basis of a combination of the modified Flory-Huggins equation (at $a_{w}=1$ ) with an expression for solubility parameter in the framework of the regular solution model [10] (Eqs. (1) and (2), respectively)

$$
\begin{aligned}
& \ln \varphi_{w}+\varphi_{p}+\chi_{w p} \varphi_{p}^{2}=0 \\
& \chi_{W P}=\frac{\bar{V}_{w}}{R T}\left(\delta_{W}^{2}-\delta_{P}^{2}\right)
\end{aligned}
$$

Inserting expression for $\chi_{W P}$ in Eq. (1) results immediately in the following final equation

$$
\ln \varphi_{w}+\varphi_{p}+\frac{\overline{V_{w}}}{R T}\left(\delta_{W}^{2}-\delta_{P}^{2}\right) \varphi_{p}^{2}=0
$$

where $\varphi_{w}$ and $\varphi_{p}$ are the volume fractions of water and a polymer respectively, and $\delta_{i}$ is the solubility parameters for water and polymer. $\chi_{W P}$ - Flory interaction parameter, $\bar{V} w$ - molar volume of water, $R$ and $T$ are gas constant and absolute temperature $(\mathrm{K})$, respectively.

The plot of Flory-Huggins equation (at water activity, $\left.a_{w}=1\right)$ in coordinates $\left(\ln \varphi_{w}+\varphi_{p}\right) v s$. $\left(\delta_{W}^{2}-\delta_{P}^{2}\right) \varphi_{p}^{2} \equiv Z$ is generally nonlinear and can be approximated by two intersectional lines in intervals: $Z \leq 600 \mathrm{~J} / \mathrm{cm}^{3}$ for the hydrophilic polymers (PVA, cellulose, chitosan and the like) and $Z \geq 800 \mathrm{~J} / \mathrm{cm}^{3}$ for the hydrophobic polymers (LDPE, HDPE, polypropylene, polystyrene, rubbers and the like), see Fig. 1. The points located in the vicinity of the intersection point of the above lines, at $600<\mathrm{Z}<800 \mathrm{~J} / \mathrm{cm}^{3}$, belong to the moderately hydrophilic polymers [11].

In Fig. 1 the water equilibrium sorption in the above systems of coordinates is presented. Two polymers (PHB and PHBV) from the family of polyhydroxyalkanoates with Hildebrand solubility parameters $\delta_{p}=19.8$ and $19.4 \mathrm{~J}^{1 / 2} / \mathrm{cm} \quad 3 / 2\left(\mathrm{~Pa}^{1 / 2}\right)$, respectively [12] are situated in the vicinity of the intersection point. The data for about 55 polymers with different hydrophilicity have been collected in our work [13]. Variation of other polymer polarity in its blend/composite with PHB (PHBV) regulates composite morphologies and, hence, both water and drug transport as well as thermophysical and mechanical behavior of polymer systems. Here we initiate our consideration with description of an utmost situation where PHB has been combined with the typical hydrophobic polymer polyethylene (LDPE).

Analyzing the micrographs obtained in our preliminary paper [14] we can distinctly discern the porous space between the continuous medium of the major phase of LDPE and the band-like fibrils of PHB. These materials have microscopically complex structure with a random distribution of pore sizes, ranging from a few microns to tens of microns. In packaging or pharmaceutical practice, in order to regulate the water permeability, the structure is slightly affected by the external force arousing during a film preparation or exploitation. Thus, controlling optimal values of the composite parameters such as porosity, permeability and hydrophilicity are important issues in PHB-PE research. 


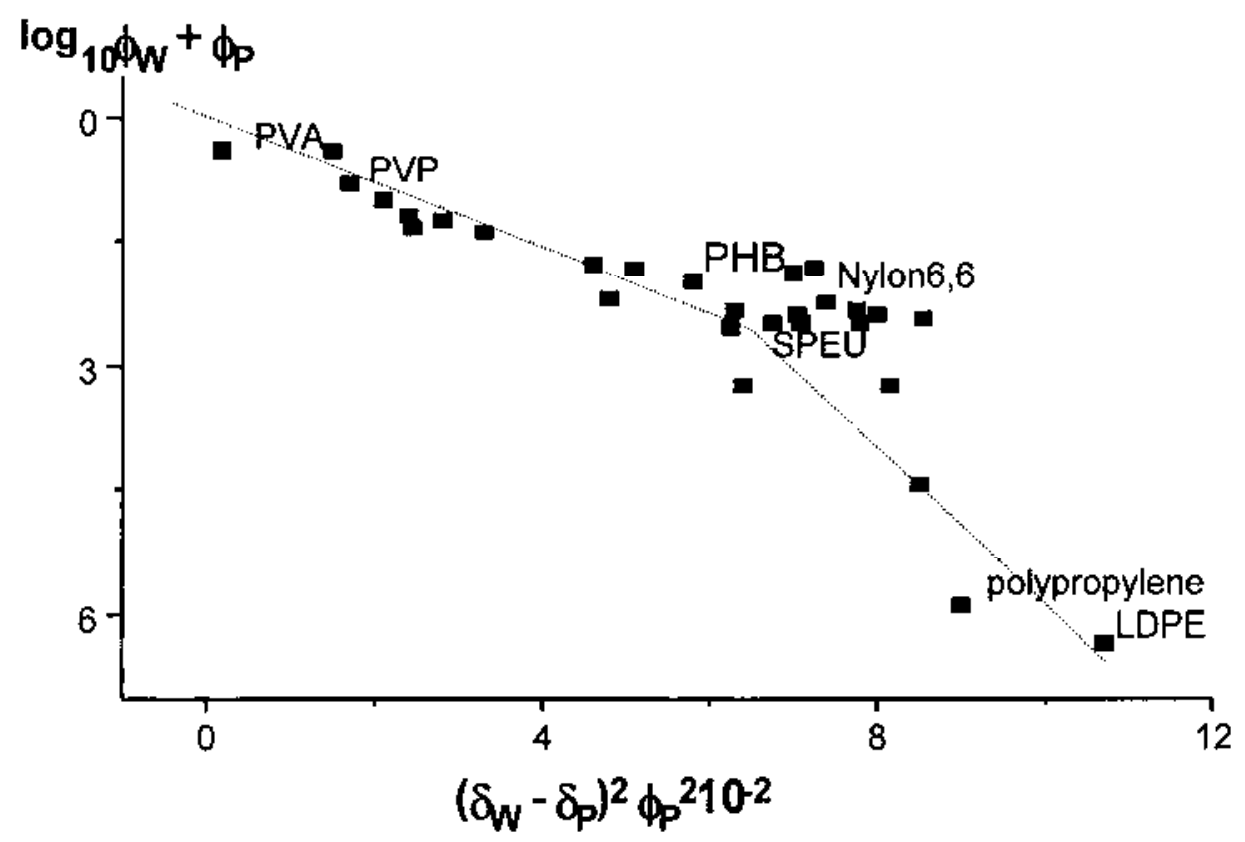

Fig. 1. The pattern of water solubility in polymers with different hydrophilicity [11] in framework of Flory-Huggins equations

\subsection{Transport Behavior of Water in the Blend of PHB with Hydrophobic Polymer (LDPE)}

The total water permeability of the LDPE/PHB blends $\left(P_{W}\right)$ can be described by the following equation:

$P_{W}=\alpha_{S}^{P E} F_{P E} P_{W}^{P E}+\alpha_{S}^{P H B} F_{P H B} P_{W}^{P H B}+\alpha_{S}^{\text {Int }}$ $P_{W}{ }^{H} \quad$ (4)

where $P_{W}{ }^{P E}, P_{W}{ }^{P H B}$ and $P_{W}{ }^{H}$ are the water permeabilities in phases of LDPE, PHB and the interphase, respectively; $\alpha_{S}{ }^{P E}, \alpha_{S}{ }^{P H B}$ and $\alpha_{S}{ }^{i n t}$ are the fractions of the film cross section possessed by the phase of each component and interphase; $F_{P E}$ and $F_{P H B}$ are function characterizing the effect of polymeric segments' orientation on the water permeability in phases of LDPE and PHB, respectively. $\alpha_{S}^{i n t}=1-\alpha_{S}{ }^{P E}-\alpha_{S}{ }^{P H B}$. In accordance with scanning electron microscopy results [14], the porous structure in the interphase is formed and, hence, parameter $P_{W}{ }^{\text {Int }}$ is equal to the hydraulic permeability [15]. Here, the porous medium is modeled as a continuum, composite material and its structure is characterized by a minimum set of properties, namely the porosity $\left(\alpha_{S}^{I n t}\right)$, the hydraulic permeability $\left(P_{W}^{H}\right)$, which might be functions of position (architecture) and structural element orientation (anisotropy) $F_{P E}, F_{P H B}$. From the local volume balance follows that:

$$
\alpha_{S}^{P E}+\alpha_{S}^{P H B}+\alpha_{S}^{I n t}=1
$$

The final term on the right hand side of Eq. (4) reflects the hydraulic movement of water through porous area and usually referred to as Darcy term [16]:

$$
J_{W}^{D a}=-K_{D a} \frac{1}{\alpha_{S} \rho_{w}} \frac{d \mu}{d x}
$$

where $J_{W}^{D a}$ is the water flow into a pore-containing area $\left(\mathrm{m}^{3}\right.$ [water] $\cdot \mathrm{m}^{-2}$ [pore cross-sectional surface area] $\left.\cdot \mathrm{s}^{-1}\right)$, $K_{D a}$ is hydraulic Darcy constant $\left(\mathrm{m} \mathrm{s}^{-1}\right)$ and $d \mu / d x$ is a water potential gradient $\left(\mathrm{m} \cdot \mathrm{s}^{-2}\right)$ expressed through the water activity or the pressure of water vapor. The expression for water permeabilities through LDPE and PHB matrices has a classical form

$$
J_{W}^{i}=-P_{W}^{i} \frac{d C_{W}}{d x}
$$

where $i$ - index used for PHB or LDPE and $\frac{d C_{W}}{d x}$ is the gradient of water concentration. Fig. 2 shows the total course of water permeability (fluxes) through the blend films as the function of PHB content. The sharp permeability jump from the matrices having the anisotropical orientation of PHB bands in LDPE to matrices where the PHB fibrils formed the isotropic network is illustrated by the corresponding photos [14] reflecting the two different types of morphology. 


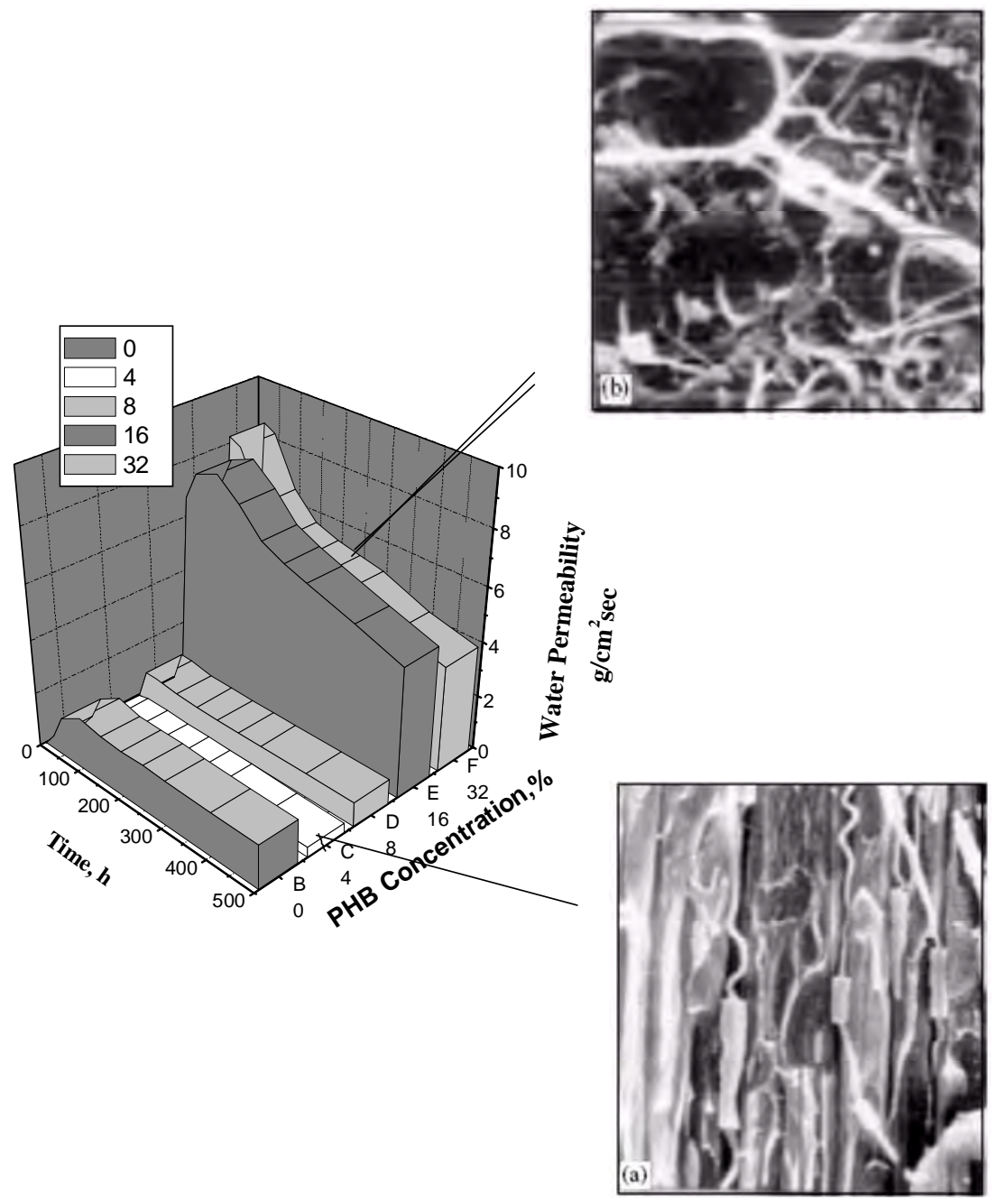

Fig. 2. Water permeability through the blend films prepared on the base of the different polymer fractions (shown on the top). Simultaneously the photo of anisotropic (a) and isotropic (b) morphologies of the blends.

The lines show the correspondence between kinetics and TEM data

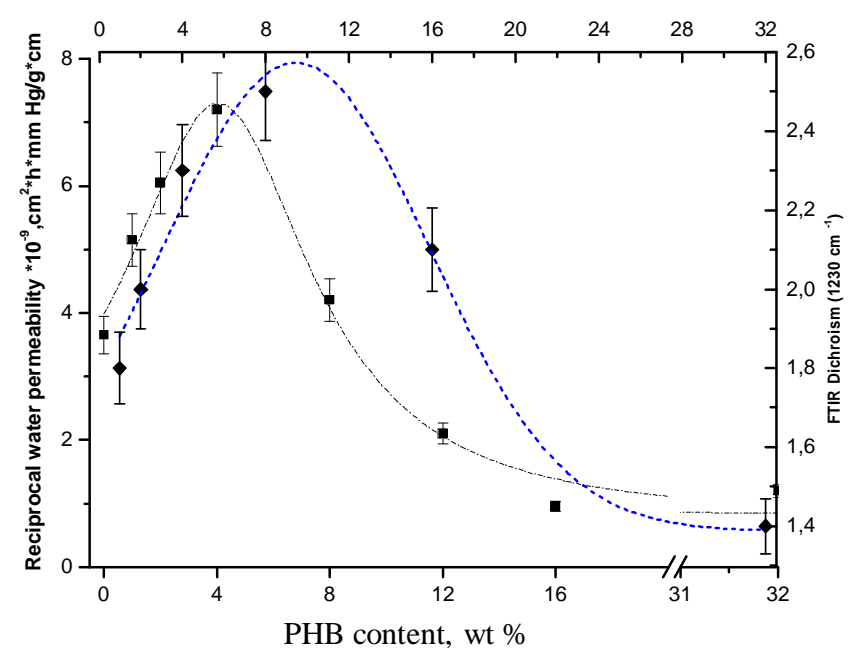

Fig. 3. Comparison of reciprocal permeability of water ( $\mathbf{\square})$, FTIR dichroism $(\diamond)$, as functions of PHB content in PHB-LDPE composite films 
At the relatively low PHB concentrations (4 to 8 wt \%), the water flux resistance is maximum and exceeds the resistance of the initial LDPE film, see Fig. 3. Then, the resistance is decreased with the increase of PHB concentration. It is significant that the same manners have both IR polarization ratios. Note that in this case tensile strength dependence on the PHB concentration with minimum is situated at the same PHB/PE fraction, about 4 to $8 \%$ (here not presented, see [14]). It is apparent from the above data that the transport behavior of water in the blended films is substantially affected by the orientation of polymer segments $\left(F_{i}\right)$ in the LDPE continuum phase and by the defects/pores formed in interphase areas $\left(\alpha_{S}^{\text {Int }}\right.$, $P_{W}{ }^{\text {Int }}$ in Eq. (1)) if one suggests that tensile strength was dominantly determined by defects (pores) of the heterogeneous matrix.

Analysis of extreme points for "transport coefficient - blend content" relationships combined with the morphology features (controlled by FTIR, XRD, SEM and AFM) and thermophysical testing (DSC, TGA) enable us to elucidate the impact of crystallinity and component nature (macromolecular polarity) upon the mechanism of both controlled release and (bio)degradation.

\subsection{Phase Transitions in the Blend of PHB with Moderately Hydrophilic Polymer (PA)}

For preparation of binary polymer composition where both components have moderate hydrophilicity (macromolecule polarity) we have selected poly(3hydroxybutyrate) [PHB] and copolymer of polyamides PA54C characterized in [17] and hereafter designated by PA acronym. One of important reasons for such selection was the proximity of their melting points $448.7 \mathrm{~K}$ (PHB) and $441.3 \mathrm{~K}(\mathrm{PA})$ and as a consequence the processing of their blends through the melt became much more efficient. The other reason is the elasticity of PA at low crystallinity and hence we would need that addition of PA to PHB could improve visco-elasticity of the neat PHB.

The assay of repeated cycles 'melting-crystallization' provided by DSC for PHB-PA composition testifies a PHB crystallinity decrease as the result of their blending. The crystallinity degree was calculated through enthalpy melting on measuring endothermic peak areas as shown in the experimental part. Under blending with moderately hydrophilic polymer (PA), the crystallinity decline resembles qualitatively the course of decrease in crystallinity for the system PHB-PVA that is at blending with a hydrophilic polymer [18]. It is important that the location of the melting point for PHB on DSC curves is displaced to low temperature area from the value $448.7 \mathrm{~K}$ for neat $\mathrm{PHB}$ to $441.5 \mathrm{~K}$ for PHB in the blend at $87.5 \% \mathrm{PA}$.

On the basis of FTIR spectroscopy data, we have shown recently [17] that in the blend films of PHB-PA there is the system of hydrogen bonds which are formed between the carbonyl group of PHB and the amide one of PA. Taking into account the accessibility of interacting groups in PHB and PA, the maximum interaction estimated as the shift of location for band maximum of carbonyl group happens at the molar ratio of PHB/PA $=1: 1$. With provision for FTIR data, we can suggest that in a chilled-down polymer composition the impact of the second component (PA) upon immobilization of PHB kinetic segments causes the decrease in their mobility and, hence, brings the drop of PHB segment fraction involved into crystallization.

The next step of blend crystallinity transfer study embraces the analysis of DSC cooling thermograms of the melts PHB-PA. For all compositions (besides the blend with the ratio of $\mathrm{PHB} / \mathrm{PA}=1: 9)$ there are two peaks with appropriate resolution on the temperature scale. Each peak belongs to the successive crystallization of individual components in the blend. It is interesting that the lowtemperature maximum reflects the crystallization of PHB melted at $\sim 448 \mathrm{~K}$ while the high-temperature peak does the crystallization of the PA melted at lower temperature, about $438 \mathrm{~K}$. Consequently, the supercooling degree (designated as the difference in the melting point and the crystallization point) is much higher for the highcrystalline PHB, relatively to PA.

For overcooled melts of the PHB blends, the addition of the second component gradually decreases the temperature of crystallization as a result of a solid crystalline phase formation in PA. The solidification of PA (its crystalline part) produces steric and kinetic hindrances effecting the PHB crystallization. Along with that, as we said above, blending of PHB with PA decreases the melting point of the former. Generally, the locations of endothermic and exothermic peaks moved on the temperature scale with such a manner that the supercooling degree keeps nearly constant. In a number of works [e.g. 18] it has been shown that both the rate of crystallinity and the rate of heterogeneous nucleation increase with the value of supercooling degree $\left(\Delta T_{C M}=\right.$ $=T_{M}-T_{c}$ ). Therefore, it is quite possible to assume that the formation of crystalline phase in PHB must be performed at the constant rate and the rate does not depend on the PHB-PA composition.

Enhancing or inhibiting in segmental mobility for the blended components reflecting the melting or crystallization can be discovered by the FTIR spectra obtained as the step-like series of temperatures. Figs. 4 and 5 show a set of spectra recorded for heated and cooled samples of PHB-PA system.

Here we have shown that stretching vibration bands of carbonyl group pertaining ester entity of PHB are very sensitive to "defrosting" in mobility of polymer molecules. Such a jump of segment mobility is the result of PHB crystal fusion. A low-frequency shoulder of 
multicomposed band of $>\mathrm{C}=\mathrm{O}$ group vibration (at $\left.1724 \mathrm{~cm}^{-1}\right)$ disappears in the vicinity of melting temperature of PHB in the PHB/PA (1:1) blend and for the blend melt above $445 \mathrm{~K}$ there is the only diffuse band with the maximum at $1740 \mathrm{~cm}^{-1}$. The extended maximum in this area most likely reflects the existence of wide distribution of mobile conformers responsible for the vibration of the ester groups in the melt. We emphasize that the temperature conforming to mobility deceleration (FTIR data) is in a good agreement with the melting point (DSC data) for PHB in the blend.

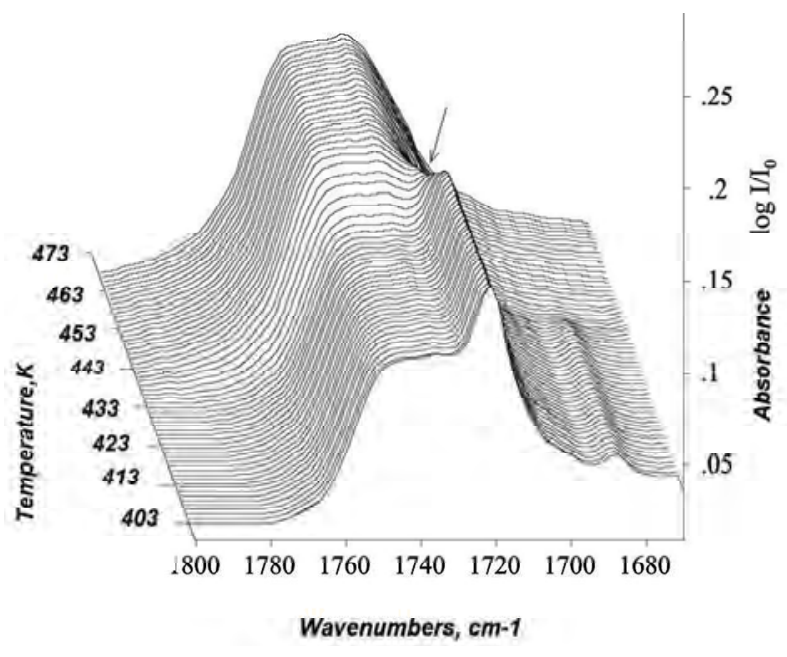

Fig. 4. FTIR-imaging for melting in the PHA-PA blend in the area of $\mathrm{C}=\mathrm{O}$ group vibration

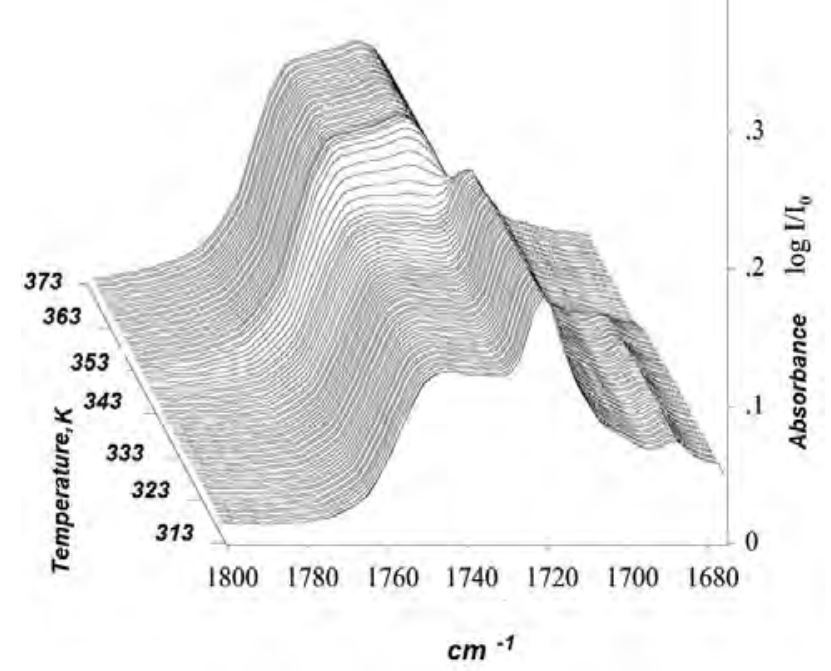

Fig. 5. FTIR-imaging for crystallization in the PHA-PA blend in the area of $\mathrm{C}=\mathrm{O}$ group vibration

The parallel temperature series has been performed under cooling of the melt blend (Fig. 5). The successive record of the FTIR spectra at different temperatures demonstrates clearly the transfer from the liquid state to the crystalline one. In the vicinity of $338 \mathrm{~K}$, this process is characterized by the sharp appearance of low-frequency mode mentioned above and related with immobilized carbonyl groups. Under blend cooling we also observe the coincidence of this temperature with the temperature interval of phase transition, measured by DSC procedure.

Summarizing the section devoted to PHB blend with a moderately hydrophilic polymer (PA) we have just shown that a phase transition is a thermo-induced process when each polymer component has the proper structure evolution and both components interact with each other. The displacements of endothemal peak $\left(T_{M}\right)$ and exothermal peak $\left(T_{c}\right)$ on the temperature scale as function of blend composition give also evidences of intermolecular interactions between the polymers forming the novel blend composition. The mechanism of thermophysical behavior can help us to design a novel therapeutic system for controlled drug delivery.

\section{Conclusions}

We propose a common simplified (relative to e.g. 3D Hansen model [19]) approach for preliminary selection of the pair of polymer components for the production of potentially partly-miscible blends. The approach is based on modified Flory-Huggins equation and used for equilibrium water sorption in polymers with different macromolecule polarity (hydrophilicity). As an example of an immiscible pair forming the blend we studied the PHB/LDPE composition. The morphological features of PHB/PE blend demonstrate the self-reinforced matrix where the minor component (PHB) forms the band-like fibrils embedded in the LDPE matrix. At the amount of PHB above $16 \%$, the blend system undergoes the morphology transfer from the oriented PHB structure to the isotropic one where the PHB fibrils transform into a network. The distinction between two morphologies reflects the different values of water permeability through the blend films.

To elucidate the role of hydrophilicity of other component presented in the PHB blends, we studied the PHB/PA blends where PA is the polyamide resin composed of statistical copolymer of hexamethyleneadipinate and $\varepsilon$-caprolactam in the ratio of 1:1. The complex of techniques including DCS and FTIR-imaging (for T-scale) demonstrates the interaction between PHB and PA in the temperature ranges of crystallization and melting. The general approach based on Flory-Huggins equation is presented as a way for choosing the pairs of compatible or partly compatible polymers. Blending PHB with PA could be a simple and effective method for designing new matrices for drug delivery in medicine, while the same procedure applied for PHB/PE-LD system with better resistance against hydrolysis and lower price than the initial PHB could be used as novel biodegradable packaging materials. 


\section{Acknowledgements}

This work was financially supported by special grant from Presidium of the Russian Academy of Sciences 2009 "Academic sciences to medicine" Project 5P-2010. The authors would like also to thank the Biomer Co (Krailing, Germany) and personally Dr. U.Hanggi for its valuable supplying with PHB.

\section{References}

[1] Chen G.: Chem. Soc. Rev., 2009, 38, 2434.

[2] Siracusa V., Rocculi P., Romani S. and Rosa M.: Trends in Food Sci. \& Techn., 2008, doi:10.1016/j.tifs.2008.07.003.

[3] Mooney B.: Biochem. J., 2009, 418, 219.

[4] Gross R. and Kalra B.: Science, 2002, 297, 803.

[5] Zhong Z., Song B. and Huang C.: Mat. Manufact. Proc., 2009, 24, 519 .

[6] Akiyama M., Tsuge T. and Doi Y.: Polym. Degrad. Stab., 2003, 80, 183.

[7] Chiellini E., Corti A., D’ Antone S. and Solaro R.: Prog. Polym. Sci., 2003, 28, 963.

[8] Gabathuler R.: Neurobiol. of Disease, 2010, 37, 48.

[9] Gonzalez-Montiel A., Keskkula H. and Paul D.: J. Polym. Sci. B, 1995, 33, 1751.

[10] Hu Y. and Hurt R.: Carbon, 2001, 39, 887.

[11] Iordanskii A.: Ch. 1 [in:] Iordanskii A., Startsev O. and Zaikov G. (Eds.), Water Transport in Synthetic Polymers. Nova Science Publishers Inc., New York 2004.

[12] Terada M. and Marchessault R.: Int. J. Biolog. Macromol., 1999, 25, 207.

[13] Iordanskii A., Rudakova T. and Zaikov G.: Ser. New Concepts in Polymer Science. VSP Science Press, 1994, 298.

[14] Ol'khov A., Vlasov C., Shibryaeva L. et al.: Polym. Sci., 2000, 42, 447.
[15] Williams C., Macpherson J., Unwin P. and Parkinson C.: Anal. Sci., 2008, 24, 437.

[16] Furmaniak S., Terzyk A., Gauden P. and Rychlicki G.: J. Food Eng., 2007, 79, 718 .

[17] Pankova Yu.: PhD thesis, Moskwa 2007.

[18] Olkhov A., Vlasov S., Iordanskii A. et al.: J. Appl. Polymer. Sci., 2003, 90, 1471.

[19] Hansen Ch., Durkee J., Barnes G. and Lyndhurst N.: 2007, ISBN-13: 9780849372483.

\section{ХАРАКТЕРИСТИКА НОВІТНІХ БІОДЕГРАДАБЕЛЬНИХ СУМІШЕЙ НА ОСНОВІ ПОЛІГІДРОКСИБУТИРАТУ}

Анотація. Вивчено нові полімерні суміші на основі полі(3-гідроксибутирату) (ПГБ) і полімерів з різною гідрофільністю (ПЕНП $і$ ПА). Для контролювання інтенсивності гідролізу і біодеградаиії приготовлено композиції ПГБ-ПЕНП $з$ різним співвідношенням компонентів і досліджено проникність води для кожного складу суміші. Встановлено вплив гідрофобного компоненту на потік води у сумімі, виходячи із зв'язку між транспортуванням води $i$ морфологією плівок. 3 використанням ДСК $i$ Фур'є-спектроскопї вивчено вплив більш гідрофільного компоненту (поліаміду 54С - статичного

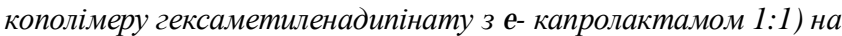
термофізичні властивості суміші (топлення і кристалізація). За допомогою модифікованого рівняння Флорі-Хаггінса встановлено можливість проводити вибір потенційних полімерних компонентів, здатних утворювати сумісні або частково сумісні композииіï.

Ключові слова: полігідроксибутират, біодеградачія, полімерні суміші, термофізичні властивості, кінетика, дифузія води. 